\title{
Comparison of magnitude estimation of loudness in children and adults'
}

\author{
DONALD D. DORFMAN AND ROBERT MEGLING \\ SAN DIEGO STATE COLLEGE
}

This study compared children (mean age 10.9 years) and college students on the magnitude estimation of loudness. Both the 20 children and the 20 adults were unpracticed observers. In one condition, the standard tone was assigned the number 10 , and in the other condition, the number 20 . Under both conditions the power function was found to fit the data of the children quite well, and to give approximately the same exponent. Of particular interest was the similarity between the data of the children and adults.

A number of studies have shown that adult observers are able to assign numbers to physical magnitudes in a quite systematic fashion. Stevens $(1956,1957,1961)$ has found that a power function fits such data quite well on a wide variety of prothetic continua, and that the exponent of the power function remains constant with changes in the numerical value of the standard. The goal of the present study was to compare children and adults on the fit of the power function and on the degree to which the exponent remains constant when the numerical value of the standard is manipulated.

\section{Method}

Subjects. The Ss were 20 boys from the Campus Laboratory School of San Diego State College and 20 male college students from an introductory psychology course at San Diego State College. None had previous experience in magnitude estimation. The ages of the children ranged from 9.9 to 11.8 years with a mean age of 10.9 years, and the adults from 18.1 to 19.2 years with a mean age of 18.7 years. The children had a mean $I C_{i}$ score of approximately 121, which was typical for a sample from this school.

Apparatus. The sound intensities were generated by a Hewlett-Packard audio signal generator (Model 205 AG), fed through a power amplifier (Heathkit, Model W7-A) and delivered to a loudspeaker (Jensen). The duration of the tones was controlled by a silenced Hunter timer (Model 111-C).

Procedure. Each $\mathrm{S}$ was tested individually in a soundproof room (Industrial Acoustics Co., Model 400-A) with the equipment in an adjacent room. Two Es were used, one inside the room with the $S$, and the second $\mathrm{E}$ outside the room controlling the equipment. The $S$ was approximately $19 \mathrm{in.}$ from the face of a loudspeaker. All tones were $1000 \mathrm{cps}$ and lasted for $1 \mathrm{sec}$. All Ss were given the same standard tone of $75 \mathrm{db}$ SPL (re $0.0002 \mathrm{dyne} / \mathrm{cm}^{2}$ ) and eight variable tones ranging from 35 to $105 \mathrm{db}$ in $10 \mathrm{db}$ steps. The sound pressure level was measured by a sound level meter (General Radio, 1551-C) with the microphone 19 in. from the face of the speaker.
Each $\mathrm{S}$ was given two blocks of 16 trials. For half of the Ss in each age-group, the standard tone was called 10 on the first block and 20 on the second block, and for the other half of the Ss, the reverse was the case. The standard tone was presented five times before each block of 16 trials was begun, with the appropriate number uttered before each presentation by the E. During these five presentations, the duration of the standard tone was 1 sec., and the interstimulus, 3 sec. Each block of 16 trials consisted of the presentation of two random sequences of the eight variable tones, with each variable tone preceded by the presentation of the standard tone. On each trial, the variable tone came on 3 sec, after offset of the standard, and the tones were presented during the utterance of the following sentence, "If this is 10,20 (standard tone presented), what number is this?" (variable tone presented). The use of 10 or 20 depended, of course, on the particular block of trials given. Each $S$ within a group was given a different random sequence of variable tones.

The instructions were as follows: "We are running an experiment to try to see how well you can tell how loud sounds are. In order to do this, we want you to give us a number for each of the sounds. We will tell you how loud the first sound is and you will tell us how loud the rest of the sounds are. These sounds will come through this speaker which is just like a radio speaker. The first sound we will call 10,20. Listen to it carefully and get it well in mind so you can compare it to the rest of the sounds. We will play the first sound five times for you. (The standard was then presented five times.) We will now play it once more and after it we will play another sound. You will tell us what number the other sound is. Remember, be sure to give bigger numbers to the louder sounds and smaller numbers to the softer sounds. Do you have any questions about this?"

After the first block of trials, the following instructions were given: "Okay, that's the end of that group. For the second group we are going to do everything just the same except we will give you another number sound. This sound is 10, 20. First, we will play the sound five times for you. We will do everything else just as before. (The standard was presented five times.) Remember to give bigger numbers to the louder sounds and smaller numbers to the softer sounds. Do you have any questions about this?"

\section{Results and Discussion}

Figure 1 shows the results obtained using the median and geometric mean as a measure of central tendency. ${ }^{2}$ The results of the children and adults appear quite simi- 


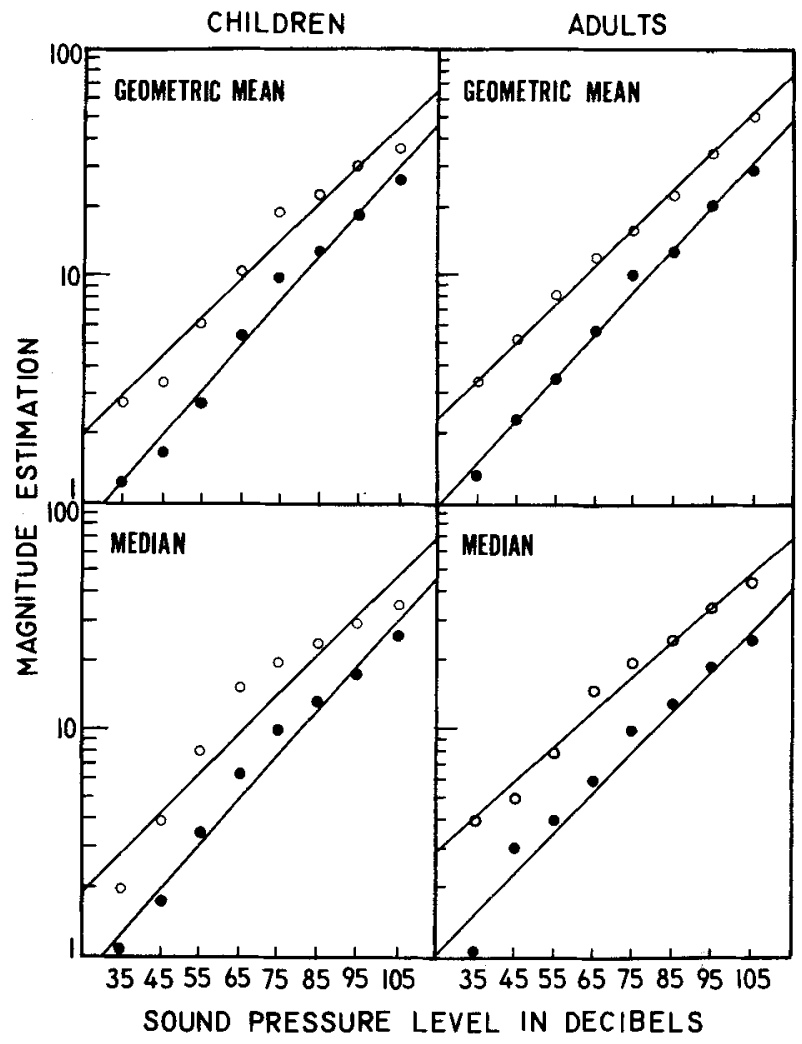

Fig. 1. Magnitude estimation as a function of sound pressure level. The filled circles show the magnitude estimations when the standard was 10 , and the unfilled circles show the magnitude estimations when the standard was 20 . Both coordinates are logarithmic.

lar. The lines drawn through the points were based on the method of least squares.

Table 1 presents the exponents of the power function and the product-moment correlations obtained from fitting the function, $\log \psi=\log \mathbf{k}+\mathrm{n} \log \phi$, to the data by the method of least squares. This function is a log transformation of the power function, $\psi=\mathrm{k} \phi^{\mathrm{n}}$, where $\psi$ is the numerical estimate, $\phi$ the physical intensity in terms of sound pressure, and $\mathrm{k}$ and $\mathrm{n}$ constants.

In addition to the results on the geometric mean and median, Table 1 also presents results on the geometric mean of subgroup medians. This is based on a measure used by Poulton and Simmonds (1963), and Poulton, Simmonds, Warren, and Webster (1965). For this meas-

Table 1. Exponents and Product-moment Correlations for $\log \psi=\log \mathbf{k}+\mathbf{n} \log \phi$ Using Different Measures of $\psi$

\begin{tabular}{lcccccc} 
& \multicolumn{3}{c}{$\begin{array}{c}\text { Exponent } \\
\text { Mean }\end{array}$ Geometric } & $\begin{array}{c}\text { Correlation } \\
\text { Mean } \\
\text { Children }\end{array}$ Median & $\begin{array}{c}\text { Mean } \\
\text { Geometric } \\
\text { Group } \\
\text { Median }\end{array}$ \\
\hline 10 & .40 & .40 & .40 & .973 & .993 & .970 \\
20 & .33 & .34 & .35 & .977 & .957 & .949 \\
Adults & & & & & & \\
10 & .35 & .38 & .37 & .996 & .995 & .979 \\
20 & .32 & .33 & .31 & .993 & .999 & .994 \\
\hline
\end{tabular}

ure, the Ss in each age-group were randomly divided into four groups of five Ss. The median of each subgroup was computed, and the geometric means of these medians were used to evaluate the power function.

As can be seen, the correlations are high for the three measures in both age-groups. In all cases, the correlations were based on the group measures. Table 1 also shows that the exponents of the children and adults are quite similar, although the children's exponents are somewhat larger. It should be noted that these exponents are smaller than the value of 0.60 given by Stevens (1961) as representative of the loudness of a $1000 \mathrm{cps}$ tone presented binaurally where $\phi$ is in terms of sound pressure. However, Stevens and Guirao (1962) point out that the method of magnitude estimation tends to underestimate the value of this exponent. With unpracticed observers, Stevens and Poulton (1956) obtained an exponent of about 0.43 with the method of magnitude estimation. This value is fairly close to the exponents obtained in this study. Also, it should be noted that this study was not specifically designed to determine the true value of the exponent. The determination of the true exponent would require further procedures which would counterbalance the regression effect observed here.

There are some detailed aspects of the data which should be noted. Although no mention of fractions appeared in the instructions, four of the children and five of the adults used fractions. As noted earlier, three of the children and none of the adults used zero. None of the children reported absence of the tone when they responded with zero, and none of the three children had a hearing difficulty according to the records of the school. It should also be noted that none of the children were discarded for failure to follow instructions.

In summary, this study has shown that children may give systematic results when asked to assign numbers to sound intensities. In fact, their data were found to be quite similar to the data obtained from unpracticed college students. It is rather surprising to the investigators that the children responded so easily to the request to assign numbers to sound intensities in spite of the fact that they were given no practice and no knowledge of how well they were doing. Of course, these findings must be restricted to children of high intelligence because of the nature of the present sample.

\section{References}

Poulton. E. C., \& Simmonds, D. C. V. Value of standard and very first variable in judgments of reflectance of grays with various ranges of available numbers. J. erp. Psychol., 1963, 65, 297-304.

Poulton, E. C., Simmonds, D. C. V., Warren, R. M., \& Webster, J. C. Prior context and fractional versus multiple estimates of the reflectance of grays against a fixed standard. J. exp. Psychol., $1965,69,496-502$.

Stevens, S. S. The direct estimation of sensory magnitudes-loudness. Amer. J. Psychol., 1956, 69, 1-25.

Stevens, S. S. On the psychophysical law. Psychol. Rev., 1957. 64, 153-181.

Stevens, S. S. The psychophysics of sensory function. In W. A. Rosenblith (Ed.), Sensory Communication. The MIT Press, 1961. Ch, 1. 
Stevens, S. S., \& Guirao, M. Loudness, reciprocity, and partition scales. J. Acoust. Soc. Amer., 1962, 34, 1466-1471.

Stevens, S. S., \& Poulton, E. C. The estimation of loudness by unpracticed observers. J. exp. Psychol., 1956, 51, 71-78.

Winer, B. J. Statistical principles in experimental design. New York: McGraw-Hill, 1962.

\section{Notes}

1. This research was supported by a grant from the National Institute of Mental Health, MH 10449-01, and by a National Science Foundation Undergraduate Research Participation Program Grant, G-6161. The authors wish to thank Gary Schneider for assistance in testing the Ss.
2. A problem arose in computing the geometric means of the children's data because three of the children gave responses of zero. Rather than remove the data of the three children from the sample, responses of zero were converted to one. Although somewhat arbitrary, this conversion was based upon the fact that the most frequent, smallest response was one. If the children were not permitted to use zero, it is very possible that they would have used one. It should be noted that only $2.3 \%$ of the children's responses were zero, and that the children's exponents computed from the geometric means were quite similar to those computed from the other measures of central tendency (Table 1).

(Received in the Editorial Office June 6, 1966.) 